\title{
O PROBLEMA DA TÉCNICA E A CRÍTICA À TRADIÇÃO NA ÉTICA DE HANS JONAS
}

\author{
Robinson dos Santos \\ Universidade Federal de Pelotas
}

\begin{abstract}
In his major writing on ethics, Hans Jonas proposes a new content for ethics and a new meaning to what we term as responsibility. On the basis of his proposition of a theory of responsibility include three key points: 1) a critique of the ethical tradition, 2) the problem of technical and 3) the heuristics of fear. These are essential to the legitimacy and understanding of Jonas' statement that "new times demand a new ethic." In the current study is to reconstruct the main arguments of Jonas for the three points mentioned.
\end{abstract}

Keywords: ethics, responsibility, nature, technique, Hans Jonas.

Resumo: Em seu principal escrito sobre ética, Hans Jonas propõe um novo conteúdo para a ética e um novo sentido para o que denominamos como responsabilidade. Na base de sua proposição de uma teoria da responsabilidade destacam-se três pontos fundamentais: 1) a crítica às éticas da tradição; 2) o problema da técnica e; 3) a heurística do temor. Estes são imprescindíveis para a legitimação e compreensão da afirmação de Jonas de que "os novos tempos exigem uma nova ética". Por meio do presente estudo pretende-se reconstruir os principais argumentos de Jonas relativos aos três pontos mencionados.

Palavras-chave: ética, responsabilidade, natureza, técnica, Hans Jonas. 
Dabei ist jedoch das eigentlich Unheimliche nicht dies, daß die Welt zu einer durch und durch technisch wird.

Weit unheimlicher bleibt, daß der Mensch

für diese Weltveränderung nicht vorbereitet ist, daß wir es noch nicht vermögen, besinnlich denkend in eine sachgemäße Auseinandersetzung mit dem zu gelangen, was in diesem Zeitalter eigentlich heraufkommt. ${ }^{1}$

(Heidegger, Gelassenheit)

\section{Introdução}

O legado de Hans Jonas é de fundamental importância para a filosofia contemporânea, especialmente no âmbito da ética. Dentre as várias razões que podem justificar sua importância, destacam-se as que seguem. Em primeiro lugar, cumpre destacar o fato de que Jonas foi um dos filósofos que ganhou mais notoriedade no período pós-guerra na Alemanha². Este feito deve-se à sua biografia pessoal e sua trajetória intelectual ${ }^{3}$. Além disso, como

\footnotetext{
1 "Com isso, o que é propriamente inquietante não é que o mundo se transforme completamente num domínio da técnica. Muito mais inquietante é que o homem não está preparado para essa transformação do mundo; que nós ainda não somos capazes de compreender adequadamente, por meio do pensamento meditativo, aquilo que está emergindo em nosssa época".

${ }^{2}$ No prólogo das Memórias [Erinnerungen] de Hans Jonas, Rachel Salamander destaca que nem Jonas, nem mesmo 0 editor Sigfried Unseld teriam imaginado tamanha receptividade e êxito na comercialização do livro O Princípio Responsabilidade (1979). "Nenhum livro de um filósofo acadêmico conseguiu no século XX, no âmbito da língua alemã, uma difusão tão rápida e ampla como este 'ensaio de uma ética para a civilização tecnológica"' (ME, p. 13). Autor de uma obra sobre a Gnose, que interessava somente a um público restrito, Jonas alcança repentinamente uma grande popularidade e torna-se uma figura requisitada pela mídia e presença marcante nos congressos e debates sobre os problemas ecológicos e o futuro do planeta. Graças ao sucesso editorial daquela obra, Jonas recebeu o Prêmio da Paz dos Editores Alemães em 1987. Sobre este aspecto vale conferir também o texto de Vittorio Hösle intitulado Hans Jonas' Stellung in der Geschichte der deutschen Philosophie, incluído na coletânea organizada por Christian Wiese e Eric Jacobson, em 2003, listada nas referências.

3 Hans Jonas nasceu em 10 de maio de 1903, em Mönchengladbach, na Alemanha. Filho de emigrantes judeus, Jonas desenvolveu já na juventude um forte vínculo com a questão da religião e aderiu ao sionismo. Em 1921, atraído pela fama de Husserl, decidiu estudar em Freiburg. Ali conheceu Martin Heidegger e, durante o mesmo período, freqüentou os seminários por ele oferecidos. É digno de nota o fascínio que o jovem professor Heidegger despertava em seus estudantes, como relata Jonas em seus depoimentos. Nesta época, Jonas conviveu e estabeleceu amizade também com Karl Löwith e Günther Stern, hoje mais conhecido como Günther Anders. Mas, ainda movido por interesses voltados ao tema do judaísmo, resolveu neste mesmo ano (1921) ir para Berlim, e matriculou-se simultaneamente na Universidade Friedrich-Wilhelms de Berlim e na Escola Superior de Ciências do Judaísmo. Leo Strauss,
} 
nenhum outro autor de sua época, Jonas chamou a atenção para um dos problemas mais sérios postos à ética do século XXI: o problema da ameaça do futuro da humanidade, da violação da integridade do ser humano e da natureza ou, numa palavra, da auto-destruição da vida do planeta; ameaça cada vez mais evidente, causada pela aposta incondicional no ideal moderno ${ }^{4}$ de progresso, enquanto exploração da natureza por meio da técnica. Diagnósticos que remontam ao anos setenta do século passado indicam os perigos e ameaças que emergem da civilização industrial: esgotamento progressivo de recursos naturais e o consequente colapso ecológico, aumento progressivo da população, ameaça de uma guerra atômica, possibilidade de manipulação genética ${ }^{5}$. Neste sentido, não seria exagero afirmar, parafraseando Karl Marx, que para Hans Jonas um espectro ronda o século XXI, a saber, o espectro de seu próprio extermínio.

Em sua obra tardia Das Prinzip Verantwortung: Versuch einer Ethik für die technologische Zivilisation (1979) [O princípio responsabilidade: ensaio de uma ética para a civilização tecnológica], Jonas expressa a

Gershom Scholem, Martin Buber, Franz Rosenzweig são alguns dos nomes com quem conviveu nesta época e que, conforme ele mesmo atesta, tiveram influência sobre sua posição relativa ao tema da religião. No semestre de inverno de 1923/24 Jonas retornou a Freiburg e, participando novamente dos seminários de Husserl, conhece também Max Horkheimer. O breve contato com Rudolf Carnap é desta mesma época. Neste período, Heidegger já estava em Marburg e Jonas decidiu mudar-se para lá, no outono de 1924. É marcante nesta época a grande amizade e convívio que estabeleceu com Hannah Arendt e com Hans-Georg Gadamer. Jonas permaneceu em Marburg até 1928, quando concluiu seus estudos de doutorado e elaborou a tese, sob orientação de Heidegger e do teólogo Rudolf Bultmann, sobre o conceito de Gnose. Em 1933 emigra para Londres e em 1934 para Jerusalém. Por recomendação de seu ex-orientador, Rudolf Bultmann, é publicada em 1934 a obra de Jonas sobre a Gnose no pensamento da antigüidade tardia. Entre os anos de 1940-1945 foi soldado na brigada judia do exército britânico. Em 1949 transferiu-se para o Canadá, onde foi professor visitante nas universidades de Montreal e Ottawa. No ano de 1955 mudou-se para Nova lorque e assumiu o cargo de professor da New School of Social Research e foi professor visitante na Columbia University, Princeton University, University of Chicago e em Munique. Suas obras principais (após o trabalho sobre a Gnose) foram publicadas de acordo com a ordem que segue: 1963 - The Phenomenon of Life: Toward a Philosophical Biology; 1973 - Organismus und Freiheit: Ansätze zu einer philosophischen Biologie; 1979 - Das Prinzip Verantwortung: Versuch einer Ethik für die technologische Zivilisation; 1985 - Technik, Medizin und Ethik: Praxis des Prinzips Verantwortung; 1992 - Philosophische Untersuchungen und metaphysische Vermutungen. Além destes escritos, Jonas tem centenas de ensaios e conferências publicados, que estão sendo reunidos para a edição das obras completas, sob a coordenação de Dietrich Böhler. Jonas recebeu diversas condecorações, prêmios e títulos honoris causa. Em cinco de fevereiro de 1993 ele faleceu em sua casa, em Nova lorque.

${ }^{4} \mathrm{O}$ ideal moderno de progresso deve ser entendido, neste contexto, como aquele embalado pela fórmula baconiana "saber é poder".

${ }^{5}$ Cf. WERNER, 2003, p. 41.

6 As obras de Jonas serão citadas com as seguintes abreviações, seguidas da paginação correspondente aos textos em alemão (com exceção das Memórias): BE: Dem bösen Ende näher; ME: 
profunda preocupação com os problemas de nossa época e procura formular um novo princípio para a ética ou, dito de outro modo, um novo imperativo para a moral pois, segundo ele, tais problemas são de uma complexidade e magnitude tamanhas, que já não podem ser enfrentados à luz das éticas da tradição ${ }^{7}$. Ele parte da centralidade que a técnica assumiu na civilização contemporânea e demonstra, tanto na obra supracitada, quanto em Technik, Medizin und Ethik: Praxis des Prinzips Verantwortung (1985) [Técnica, medicina e ética: prática do princípio responsabilidade], porque ela se tornou um objeto da filosofia e, com isso, também um objeto da ética.

A crítica à técnica é, pois, um dos aspectos centrais na formulação de sua proposta e, com isso, é necessário o esclarecimento da perspectiva que ele assume quanto a ela, na medida em que também outros pensadores, contemporâneos de Jonas, sobretudo Heidegger e Günther Anders, por exemplo, também se ocuparam com tal questão ${ }^{8}$. Com efeito, no prefácio de $P V$ (p. 7) afirma Jonas: "A tese de partida deste livro é que a promessa da tecnologia moderna se converteu em ameaça, ou esta se associou àquela de forma indissolúvel”. Não se trata de uma visão pessimista, que poderia ser vista até mesmo como simplória no sentido de uma mera satanização da técnica, mas da constatação de seu poder real de destruição, que a acompanha como sua sombra, seguida de uma cuidadosa e contundente argumentação, ainda pouco explorada em nosso cenário filosófico, tanto em suas possibilidades, quanto em seus aspectos problemáticos.

No entender de Jonas, é justamente o "sucesso" da técnica que devemos temer e não o seu fracassso, pois o que está em jogo neste desempenho é, nada mais e nada menos, do que o futuro da humanidade inteira e do planeta que habitamos. Estes, conforme argumenta Jonas, não podem ser objetos de aposta. Eis o que implica, a grosso modo, uma nova postura na relação com o mundo: uma relação pautada pela responsabilidade.

Memorias [trad. espanhola]; PV: Das Prinzip Verantwortung:Versuch einer Ethik für die technologische Zivilisation; TME: Technik, Medizin und Ethik: Praxis des Prinzips Verantwortung.

${ }^{7}$ A crítica de Jonas não se dirige a uma ou outra posição em particular e de modo explícito, num primeiro momento. É possível perceber, no entanto, que a referência é feita, sobretudo, à ética aristotélica e kantiana.

${ }^{8}$ Vale conferir as obras de Heidegger Die Frage der Technik (1954), Die Technik und die Kehre (1962) e Gelassenheit (1959). As obras principais de Günther Anders para uma crítica da técnica são Die Antiquiertheit des Menschen 1: Über die Seele im Zeitalter der zweiten industriellen Revolution (1956) e Die Antiquiertheit des Menschen 2: Über die Zerstörung des Lebens im Zeitalter der dritten industriellen Revolution (1980). 
Neste ensaio serão abordados três aspectos, entre os diversos considerados por Jonas na elaboração de sua teoria da responsabilidade: 1) a crítica às éticas da tradição; 2) o problema da técnica e; 3) a heurística do temor. Estes três aspectos permitem, em certa medida, compreender a afirmação de Jonas de que "os novos tempos exigem uma nova ética". Por se tratar de uma primeira incursão pelo pensamento do autor, não está em questão, neste momento, um julgamento geral ou definitivo sobre a legitimidade de sua proposta. A compreensão deste ponto de partida é, no entanto fundamental para a avaliação de sua proposta, algo que será levado a cabo na pesquisa que vem sendo desenvolvida. Deste modo, é necessário esclarecer, inicialmente, o que ele quer dizer com a afirmação de uma "natureza modificada do agir humano", bem como demonstrar por que esta impõe uma reformulação para a ética.

\section{As limitações da ética da tradição}

O primeiro capítulo de $P V$ tem como objeto de análise o que Jonas concebe como "a natureza modificada do agir humano"'. A natureza modificada do agir se dá pelo fato irreversível da técnica ter se tornado constitutiva na relação do ser humano com o mundo. Com efeito, "vivemos a técnica irremediavelmente, sem possibilidade de escolha" ${ }^{10}$. Se a ação humana é um conceito central na ética e, conforme Jonas, foi transformada em suas características e conteúdo, logo é preciso transformar também a ética. Aqui o conceito de mudança ou transformação do agir humano deve ser compreendido como um acréscimo qualitativo e quantitativo que a técnica incorporou na ação. A ação humana teve sua esfera de alcance progressivamente ampliada por meio da melhoria contínua dos “meios”. E a técnica foi historicamente o principal dentre aqueles. É preciso esclarecer,

\footnotetext{
9 O conceito de ação (e com ele relacionado, o conceito de liberdade) é, como se sabe, elementar no âmbito da moral. Só podemos falar de ação na medida em que atribuímos a este conceito uma definição que o distingue de acontecimentos ou fenômenos que estão submetidos à causalidade natural. Neste sentido, o conceito de ação implica a pressuposição de um sujeito agente ou atuante, na medida em que este procura realizar algo através da ação. Entre outras características, encontramos na ação humana traços mais ou menos evidentes de intencionalidade, espontaneidade e liberdade da vontade. Cf. HESSE, 2006, p. 396.

${ }^{10}$ GALIMBERTI, 2006, p. 8. Merece destaque neste âmbito o estudo amplo sobre o problema da técnica de que este autor oferece.
} 
todavia, de que a técnica de que Jonas fala, é a técnica moderna ${ }^{11}$. Esta, conforme observa ele, "introduziu ações de uma tal ordem inédita de grandeza, com tais novos objetos e consequências que a moldura da ética antiga não consegue mais enquadrá-las" ( $P V$, p. 26).

Para validar sua posição e destacar em que aspecto ela se distancia da tradição, Jonas precisa indicar as limitações ou, pelo menos, aspectos problemáticos da concepção de ação presentes na ética tradicional. A tese que abre o primeiro capítulo de $P V$, é assim postulada:

Toda ética até hoje - seja como injunção direta para fazer ou não fazer certas coisas ou como determinação dos princípios de tais injunções, ou ainda como demonstração de uma razão de se dever obedecer a tais princípios - compartilhou tacitamente os seguintes pressupostos inter-relacionados: (1) a condição humana, conferida pela natureza do homem e pela natureza das coisas encontra-se fixada de uma vez por todas em seus traços fundamentais; (2) com base nesses fundamentos, pode-se determinar sem dificuldade e de forma clara aquilo que é bom para o homem; (3) o alcance da ação humana e, portanto, da responsabilidade humana é definido de forma rigorosa. A argumentação que se segue pretende demonstrar que esses pressupostos perderam a validade $e$ refletir sobre o que isso significa para a nossa situação moral.(PV, p. 15)

A primeira constatação, como se pode perceber, refere-se a pressuposição, ainda que tácita, de uma imagem humana determinada ou definida de forma precisa, subjacente naquelas formulações a respeito do que é bom ou justo. No limite, tal pressuposição poderia ser vista como a identificação de uma "essência" humana e, por conta de haver uma, seria possível deduzir, justamente por meio dela, o conceito do que é bom e

\footnotetext{
11 Neste sentido é importante a distinção que ele faz em $T M E$, sobretudo na primeira parte. A técnica pré-moderna tem para Jonas um conjunto de atributos que a diferencia da técnica moderna. Aquela pode ser vista como uma posse e estado, isto é, no conjunto de ferramentas e procedimentos disponíveis haveria uma certa constância e uma tendência ao equilíbrio entre fins e meios. Nesta, as revoluções que se sucederam devem-se, conforme 0 autor, mais a casualidades que a intenções. $A$ técnica moderna indica, ao contrário, uma empresa e um processo, isto é, "cada novo passo em qualquer direção (...) não conduz a um ponto de equilíbrio ou 'saturação' na adequação dos meios aos objetivos pré-fixados mas, ao contrário, no caso de êxito constitui o motivo para das outros passos em todas as direções possíveis" (TME, p. 19).
} 
estabelecer de modo inconfundível o que seria responsabilidade para o homem. Cumpre assinalar, no entanto, que por tratar-se de uma tese generalizante, fica difícil compreender a qual das éticas da tradição é endereçada esta caracterização em particular (se esta se refere à ética da Antiguidade, Medieval ou Moderna). Deste modo a afirmação "Toda ética até hoje” parece não fazer nenhuma exceção e igualar todas as éticas (aristotélica, kantiana e utilitarista, para citar apenas alguns exemplos) em torno daqueles três pressupostos. Mesmo assim, esta tese permanece problemática e aqui Jonas fica devendo um esclarecimento mais detalhado.

Por outro lado, através de tais constatações Jonas visa também evidenciar o caráter eminentemente antropocêntrico da ética tradicional. Para ele a ética permaneceu, ao longo da tradição, centrada no homem e, primeiramente, reduzida ao âmbito da polis. Neste caso a remissão é, ainda que implícita, endereçada a Aristóteles. Jonas enfatiza que, por conta disso, os esforços no campo da filosofia moral sempre ignoraram o tema da relação homem-natureza ${ }^{12}$.

Todo o trato com o mundo extra-humano, isto é, todo o domínio da techne (habilidade) era - com exceção da medicina - eticamente neutro [...] Em suma, a atuação sobre objetos não humanos não formava um domínio eticamente significativo. [...] A significação ética dizia respeito ao relacionamento direto do homem com o homem, inclusive o do homem consigo mesmo; toda ética tradicional é antropocêntrica $(P V$, p. 22)

Ao limite antropocêntrico da ética tradicional soma-se outra característica apontada por Jonas, a qual refere-se ao alcance de sua ação no tempo e no espaço. O bem ou o mal decorrentes da ação permaneciam circunscritos a um âmbito calculável e de curto prazo. Aspectos como a condição global da vida humana, a vida das gerações futuras e das demais espécies do planeta, bem como o futuro longínquo não constituíram historicamente o pano de fundo das reflexões e proposições éticas. "O longo trajeto das consequências ficava ao critério do acaso, do destino ou da

${ }^{12}$ Este "esquecimento" da ética tradicional será sempre mencionado em suas entrevistas como, por exemplo em BE, p. 13. 
providência. Por conseguinte, a ética tinha a ver com o aqui e agora, como as ocasiões se apresentavam aos homens [....]" (PV, p. 23).

O círculo imediato da ação é, portanto, o ponto comum para o qual convergem, em última instância, todas as preocupações contidas nas normas morais postuladas na tradição. São os que convivem no mesmo espaço e tempo ou aqueles que são afetados pela ação do sujeito agente (fazendo algo ou deixando de fazê-lo) que constituem o universo moral no qual ele se movimenta. São aqueles, naquele momento, que impõem ao agente uma exigência de responsabilidade. De algum modo isto fica evidente nas máximas vinculadas à tradição, de cunho religoso ou não, tais como: "Ama a teu próximo como a ti mesmo", "Faze aos outros o que gostaria que fizessem a ti", "Nunca trates os teus semelhantes como simples meios, mas sempre como fins em si mesmos".

Jonas define esta forma de pensar e agir como ética da simultaneidade. Com estes dois aspectos problemáticos, isto é, através deste caráter vinculado ao presente e marcadamente centrado no homem, tanto futuro distante e desconhecido quanto o todo o mundo extra-humano (a biosfera) são desconsiderados para a reflexão em torno dos princípios da moral.

Se uma ação é "boa" ou "má", tal é inteiramente decidido no interior desse contexto de curto prazo. Sua autoria nunca é posta em questão, e sua qualidade moral é imediatamente inerente a ela. Ninguém é julgado responsável pelos efeitos involuntários posteriores de um ato bem-intencionado, bemrefletido e bem-executado. $(P V$, p. 25$)$

Jonas insistirá que este é um dos grandes limites da ética que herdamos. O futuro é, ao mesmo tempo, condição de possibilidade de continuidade da humanidade e também o espaço dos efeitos possíveis e longínquos da ação humana. É justamente a partir destas limitações que Jonas legitima a necessidade de uma nova ética para os novos tempos. Esta deve ter como horizonte de sua projeção o futuro desconhecido, incluindo nele o direito dos que ainda não existem e ter como centro de referência não apenas o homem, mas a vida do cosmos, isto é, a totalidade daquilo que vive. Com isso em lugar da ética antropocêntrica é reinvindicada uma ética bio- ou cosmocêntrica.

Se assim for, isso requereria alterações substanciais nos fundamentos da ética. Isso significaria procurar não só o bem humano, mas também o bem das coisas extra-humanas, isto é, 
ampliar o reconhecimento de 'fins-em-si-mesmos' para além da esfera do humano e incluir o cuidado com estes no conceito de bem humano.(PV, p. 29)

Levando em consideração esta mudança paradigmática no plano da fundamentação da ética e realizando um percurso implicitamente kantiano ${ }^{13}$, Jonas examinará novamente a possibilidade de estabelecer um princípio supremo - um novo imperativo - para a ética. Este deve, por conseguinte, atender a demanda de uma dupla superação, a saber, do antropocentrismo e do caráter de simultaneidade apontados acima. Em sua crítica e reformulação do imperativo categórico de Kant, Jonas assim observa:

O imperativo categórico de Kant dizia: 'Aja de modo que tu possas querer que tua máxima se torne lei universal.' Aqui, o 'que tu possas' invocado é aquele da razão e de sua concordância consigo mesma: a partir da suposição da existência de uma sociedade de atores humanos (seres racionais em ação), a ação deve existir de modo que possa ser concebida sem contradição, como exercício geral da comunidade. Chame-se atenção aqui para o fato de que a reflexão básica da moral não é propriamente moral, mas lógica: o 'poder' ou 'não poder' querer expressa autocompatibilidade ou incompatibilidade, e não aprovação moral ou desaprovação.( $P V$, p. 35)

A esta observação, Jonas irá acrescentar que o que deve ser levado em consideração, em lugar da concordância consigo mesmo, é a idéia de que a a vida humana e todas as outras formas de vida permaneçam como possíveis sobre a terra. Deste modo, ele irá propor sua própria versão do novo imperativo, como será demonstrado. Neste contexto, mais do que as fórmulas possíveis, é importante enfatizar o caráter do novo imperativo:

O novo imperativo clama por outra coerência: não a do ato consigo mesmo, mas a dos seus efeitos finais para a continuidade da atividade humana no futuro. E a 'universalização' que ele visualiza não é hipotética, isto é, a transferência meramente lógica do 'eu' individual para um 'todos' imaginário, sem conexão causal com ele ('se cada um

${ }_{13}$ Cf. BÖHLER, 2004, p. 102. 
fizesse assim'): ao contrário, as ações subordinadas ao novo imperativo, ou seja, as ações do todo coletivo, assumem a característica da universalidade na medida real de sua eficácia. Elas 'totalizam' a si próprias na progressão de seu impulso, desembocando forçosamente na configuração universal do estado de coisas. Isso acresce ao cálculo moral o horizonte temporal que falta na operação lógica e instantânea do imperativo kantiano: se este último se estende sobre uma ordem sempre atual de compatibilidade abstrata, nosso imperativo se estende em direção a um previsível futuro concreto, que constitui a dimensão inacabada de nossa responsabilidade $(P V, 37-38)$

Sob a perspectiva de uma ênfase sobre os "efeitos finais" da ação no futuro, a ética da responsabilidade poderia ser interpretada como uma ética utilitarista, no sentido de que as consequências produzidas pelas ações definem se as mesmas são moralmente boas ou más. Apesar de Jonas referirse nesta passagem à previsão de um futuro concreto, sua ética distancia-se do utilitarismo clássico, na medida em que não se trata meramente de calcular os efeitos finais das ações. E, note-se que ele se refere aos efeitos imprevisíveis e incalculáveis, o que elimina a possibilidade de qualquer antecipação.

Por outro lado, a ética jonasiana é, em certa medida, herdeira da ética kantiana pois Jonas pretende fundamentar uma idéia de dever. Este dever está relacionado com as futuras gerações. A diferença fundamental está em que para Jonas a responsabilidade seria centrada numa relação assimétrica e não recíproca de cuidado, isto é, numa espécie de relação de mão-única em que o bem que fazemos não recebe ou reclama retribuição. Para Kant, grosso modo, não se trata de semelhante relação e sim de uma relação de iguais e, portanto, de justiça (âmbito da legalidade) e responsabilidade (âmbito da moralidade) recíprocas entre os sujeitos. Tal relação fica evidenciada, no plano da moral, na idéia de um reino dos fins conforme a argumentação kantiana na Grundlegung zur Metaphysik der Sitten ${ }^{14}$.

\footnotetext{
${ }^{14} \mathrm{~A}$ formulação deste conceito é caracterizada por Kant nesta obra [GMS], na segunda seção, em BA 74: "O conceito segundo o qual todo o ser racional deve considerar-se como legislador universal por todas as máximas da sua vontade para, desse ponto de vista, se julgar a si mesmo e às suas ações, leva a um outro conceito muito fecundo que the anda aderente e que é o de um Reino dos Fins.[] Por esta palavra reino entendo eu a ligação sistemática de vários seres racionais por meio de leis comuns." A citação de Kant é feita aqui de acordo com a edição organizada por Wilhelm Weischedel, listada nas referências.
} 
O (im)previsível futuro concreto, isto é, a certeza de que haverá um, está para o imperativo, como o efeito desconhecido está para a ação. Ambos são destinos, respectivamente. Exatamente pelo fato de desconhecermos completamente os efeitos longínquos que até mesmo as ações bem intencionadas produzem, é que precisamos de uma precaução redobrada.

\section{Técnica e catástrofe potencializada}

Embora Jonas tenha iniciado sua carreira intelectual e sua obra filosófica com uma investigação sobre a gnose, no seu doutorado e, posteriormente, tenha se dedicado à filosofia da biologia, ele volta-se nos anos 70 para problemas no âmbito da ética, advindos do desenvolvimento científico e tecnológico. Em sua conferência intitulada Wissenschaft als persönliches Erlebnis [Ciência como vivência pessoal], que é uma espécie de autobiografia intelectual, ele relata que sua obra pode ser vista em três fases principais. A primeira é marcada pelo estudo sobre a gnose na Antiguidade, a segunda pelo interesse sobre uma ontologia do orgânico e a terceira por sua ética da responsabilidade. Mesmo que aparentemente as fases não estejam diretamente conectadas entre si, há entre elas uma unidade de pensamento que, não obstante, impõe dificuldades e não está isenta de problemas.

A passagem citada em seguida, ilustra, em poucas linhas, de modo lapidar a dimensão que o problema da técnica assume no mundo contemporâneo para o autor, bem como imprime a necessidade sentida por Jonas de uma compreensão profunda e abrangente do problema (uma filosofia da tecnologia).

É porque a técnica, hoje em dia, interfere em quase tudo o que diz respeito ao ser humano - viver e morrer , pensar e sentir, agir e padecer, ambiente e coisas, desejos e destino, presente e futuro - , em suma, dado que ela se tornou um problema tanto central quanto ameaçador da existência humana global sobre a terra, que ela, por meio disso, se converte também numa questão da Filosofia. Com isso, faz-se necessário algo como uma Filosofia da Tecnologia (TME, p. 15). 
Com estas palavras é que Jonas abre o primeiro capítulo de $T M E$, obra na qual ele procura refletir sobre as possibilidades de aplicação ${ }^{15}$ de seu princípio da responsabilidade, desenvolvido anteriormente em $P V$. Sua preocupação indica o quanto é inquietante e delicada a situação de uma sociedade que, progressivamente, estabelece o critério para avaliar o grau seu desenvolvimento, a partir dos avanços da ciência e da tecnologia. Em uma das entrevistas, que fazem parte de $B E$ Jonas enfatiza que a técnica há muito extrapolou seu sentido meramente instrumental: "Ela modifica efetivamente a natureza, as condições da vida do homem e também os fins da vida humana” ( $B E$, p. 85). Neste sentido, Jürgen Habermas indica em seu texto (que é também o título do livro) Technik und Wissenschaft als Ideologie [Técnica e ciência como ideologia] que desde o final do século XIX um processo peculiar acompanha o capitalismo tardio: a cientificação da técnica [die Verwissenschaftlichung der Technik]. Ali ele evidencia, entre outros aspectos, o quanto a pressão institucional do sistema estava voltada ao aumento da produtividade através das inovações técnicas. Mas até então - e nisso ele sua análise concorda em boa medida com a de Jonas - estas inovações aconteciam de modo espontâneo ou natural, embora pudessem ser fomentadas por meio da economia. Todavia, argumenta que:

Isso modificou-se, na medida em que a evolução da técnica é realimentada com o progresso das ciências modernas. Com a investigação industrial de grande estilo, a ciência, a técnica e a revalorização do capitalismo confluem num único sistema. [...]Como variável independente aparece então um progresso quase autônomo da ciência e da técnica, do qual depende de fato outra variável mais importante do sistema, a saber, o crescimento econômico. Resulta deste modo uma perspectiva na qual a evolução do sistema social parece estar determinada pela lógica do progresso técnico-científico. (HABERMAS, 1973, p. 79)

Jonas, desenvolvendo uma argumentação com pendor nitidamente marcado pela terminologia teológica em algumas passagens, afirma que a técnica adquiriu, na sociedade contemporânea, as mesmas características que

\footnotetext{
15 Os estudos ali desenvolvidos se destinam a problemas como o experimento da medicina com seres humanos, a clonagem, morte cerebral, eutanásia e doação de órgãos.
} 
antes eram atribuídas à divindade, a saber, a onipotência e a onipresença. Este poder possibilitado pelo avanço da ciência representa uma força e um potencia ${ }^{16}$ jamais considerados em qualquer período anterior da história e, certamente, esta é uma das razões que faz com que as éticas tradicionais tenham, ante problemas atuais, um alcance limitado. Se de um lado elas continuam válidas para pensarmos sobre certos problemas, por outro, não são suficientes ou não possuem elementos para enfrentarmos novos desafios. Sobre este ponto a posição de Jonas é clara:

Decerto que as antigas prescrições da ética "do próximo" - as prescrições da justiça, da misericórdia, da honradez etc. ainda são válidas, em sua imediaticidade íntima, para a esfera mais próxima, quotidiana, da interação humana. Mas essa esfera torna-se ensombrecida pelo crescente domínio do fazer coletivo, no qual ator, ação e efeito não são mais os mesmos da esfera próxima. Isso impõe à etica, pela enormidade de suas forças, uma nova dimensão, nunca antes sonhada, de responsabilidade. ( $P V$, p. 26)

Precisamente por não haver mais um ponto de saturação na resolução da equação meios-fins, é que para cada passo dado no desenvolvimento da técnica surgem "novas necessidades" que demandam novos processos de desenvolvimento, que por sua vez propiciarão novas necessidades possibilitando uma cadeia ininterrupta cada vez mais autônoma. Esta centralidade da técnica e sua autonomização promovem uma colonização cada vez maior sobre a esfera das relações do ser humano. Neste sentido, o conceito elaborado por Marx e Engels de reificação ou coisificação (Verdinglichung), retomado por Lucácks e outros autores contemporaneamente, permanece válido no contexto de argumentação de Jonas. A infatigabilidade deste processo culmina em desumanização do ser humano, bem como no extermínio inescrupuloso da natureza. Consequentemente é vedado, neste contexto, conferir ou atribuir dignidade para a natureza. Ela é

\footnotetext{
${ }^{16}$ Cumpre apontar, sobretudo, para o seu potencial destrutivo, como argumenta Birnbacher (2003). 0 autor destaca três características fundamentais da técnica moderna. Para ele, esta precisa ser compreendida a partir de sua tecnicidade, globalidade e potencial de destruição. A tecnicidade não consiste em uma redundância, mas é indicada no sentido de sua base progressivamente autônoma e aliada à ciência. A globalidade refere-se ao alcance imediatamente universal dos efeitos e o potencial de destruição se equipara à capacidade de inovação e ao alcance global.
} 
vista sempre como algo que não tem valor em si. Deste modo, a proposta de uma ética para a civilização tecnológica pautada pelo princípio da responsabilidade oferece subsídios para (re)pensar a dignidade humana e da natureza em novas bases.

Para Jonas a figura que melhor representa o ser humano na era da técnica é a imagem de Prometeu desacorrentado. Liberado do castigo eterno dos grilhões e da ave de rapina que vem lhe devorar o fígado, agora ele está entregue unicamente a si mesmo. É justamente por se ver livre e com poderes sempre mais eficazes que a ameaça iminente de um novo "castigo" se coloca no destino daquele que se compadeceu com os humanos. No prefácio de $P V$ ele declara:

O Prometeu definitivamente desacorrentado, ao qual a ciência confere poderes jamais conhecidos e a economia o impulso irrefreável, clama por uma ética, que através de um freio voluntário detenha seu poder de ser a desgraça para o homem. Que a promessa da técnica moderna se converteu em ameaça, ou que esta se juntou àquela de modo indissolúvel, eis o que configura a tese que é o ponto de partida deste livro $(P V$, p. 7).

A técnica é uma forma específica da ação humana e configura, portanto, um âmbito no qual a liberdade do sujeito é exercida. Dada a necessidade vital do ser humano valer-se de suas disposições e aptidões, o conhecimento torna-se, ao longo da história humana, imperioso, condição de possibilidade do seu vir-a-ser. Com razão, Oswald Spengler definia a técnica como Taktik des Lebens [tática da vida] ${ }^{17}$. Se nos primórdios da humanidade ela representava uma condição de possibilidade do vir-a-ser humano na perspectiva cultural, nos tempos atuais poderíamos afirmar que ela é condição de possibilidade do vir-a-ser humano também na perspectiva biológica. Isso corrobora o que Jonas quer evidenciar quando fala que a técnica ultrapassou há muito o sentido meramente instrumental e que ela cria novos fins para a vida humana. Galimberti (2006, p. 519) observa que na era da técnica, "a ética celebra a sua impotência". Ela não consegue frear o impulso autômato da técnica, que estabelece fins para a vida humana à

17 Neste sentido, vale conferir o texto do autor Der Mensch und die Technik: Beiträge zu einer Philosophie des Lebens. 
revelia da ética. O conhecimento - leia-se neste contexto o saber fazer representa, não apenas in thesi, mas de fato, um poder que está nas mãos humanas, tal como proclamado pela expressão baconiana, mas que paradoxalmente se subtrai ao seu controle. $\mathrm{Na}$ medida em que a capacidade de conhecer está diretamente relacionada à faculdade de agir humana e, portanto, à liberdade, tudo o que é proporcionado por ela não pode ser isento de consideração valorativa. Deste modo, a técnica está sujeita, como toda e qualquer forma de ação humana ou resultado da mesma, ao crivo da ética. Como qualquer faculdade ou capacidade dos seres humanos a técnica não é, em si, algo ruim e nem, tampouco, poderia ser rotulada a priori de "má". Pelo contrário, no entender de Jonas, qualquer capacidade humana é, em si, algo bom (TME, p. 42); é apenas o seu mau emprego que gera consequências negativas e danosas para o próprio ser humano.

Estas proposições, embora compartilháveis e passíveis de concordância num primeiro momento, escondem, porém, alguns problemas que dão margem a uma série de objeções. A primeira é a de que, embora se possa concordar que a técnica é uma forma de ação humana, mas que por isso está sujeita per se ao julgamento moral, não é tão óbvio como Jonas quer evidenciar $^{18}$. Ele junta novamente aquilo que Aristóteles já havia diferenciado e separado, a saber, as esferas da praxis e da poiesis e seus respectivos saberes, a phronesis e a techne. Com isso sua ética ficaria vulnerável por faltar com o rigor metodológico e esmaecer em última instância a própria moral. Por outro lado, ao defender a idéia de que a técnica não é boa nem má e afirmar que o seu uso é que determina tal valor, não estaria Jonas incorrendo numa espécie de falácia da neutralidade da técnica? ${ }^{19}$

Outro aspecto problemático merece destaque neste contexto. Jonas chama atenção para o mesmo e até mesmo reconhece que, talvez, é aquele que mais implica em dificuldades de aceitação. Trata-se do fato de que não é apenas o mau uso ou mau emprego da técnica que provoca o mal na civilização e que representa uma ameaça concreta ao ser humano e à natureza. A questão fundamental é que também e, principalmente, a técnica em seu emprego positivo, benéfico para a civilização traz consigo, contrabandeado, um potencial ameaçador. Nesta perspectiva, afirma Jonas,

\footnotetext{
${ }^{18} \mathrm{BECCHI}, 1989$, p. 25.

${ }_{19}$ GALIMBERTI (2006, p. 8) argumenta, neste sentido que: "A técnica não é neutra, porque cria um mundo com determinadas características com as quais não podemos deixar de conviver e, vivendo com elas, contrair hábitos que nos transformam obrigatoriamente".
} 
referindo-se à técnica, que o perigo está mais no seu sucesso do que no seu fracasso (TME, p. 43).

A consideração de que é, justamente, no sucesso da técnica que temos uma ameaça implica em uma nova consideração a ser feita no âmbito da ética. E aqui aparece o indício principal para uma resposta àquela primeira objeção formulada anteriormente. Jonas caracteriza o sucesso da técnica por meio da sobreposição do homo faber ao homo sapiens. Por meio esta distorção ou inversão da imagem humana implica numa revisão dos princípios: "Se a esfera do produzir invadiu o espaço do agir essencial, então a moralidade deve invadir a esfera do produzir, da qual ela se mantinha afastada anteriormente" ( $P V$, p. 32). Hannah Arendt, que também se debruçou sobre este problema em sua Vita Activa, destacou o problemático "equacionamento da inteligência com a engenhosidade" ${ }^{20}$, como processo típico da modernidade. Deste equacionamento somos herdeiros sem direito à devolução.

A ação humana tendo seu espectro hiperpotencializado abre espaço para um novo leque de questões e problemas que exigem o (re)dimensionamento da reflexão ética e (re)coloca no centro do debate um conceito já conhecido, mas que nunca esteve tão implicado com este desenvolvimento: a questão da responsabilidade. "Com aquilo que fazemos aqui e agora e, quase sempre, com o olhar sobre nós mesmos, influenciamos massivamente a vida de milhões em outros lugares e no futuro, que não tiveram voz aqui e agora" (TME, p. 45). Em outras palavras, a ação humana potencializada pela técnica implica em que se reflita sobre a ameaça concreta à vida humana e à natureza. Além disso, tal reflexão não pode considerar apenas as conseqüências, sejam elas positivas ou negativas, para a civilização do presente, mas também as conseqüências possíveis para as gerações futuras. É sobre este caráter apocalíptico e catastrófico da técnica bem sucedida que devemos refletir. Em lugar de permanecermos na posição segura - e ilusória de quem controla a força da técnica, é preciso que desenvolvamos uma postura de reverência e de temor. "Quando a esperança não é mais a inspiração, então talvez seja o alerta do medo o que pode nos conduzir à razão" ( $B E$, p. 90). Para isso Jonas propõe que façamos uma heurística do temor. $\mathrm{O}$ que ele quer propor com isso e o que este termo significa é o que passo a abordar em seguida.

${ }^{20}$ ARENDT, 2006, p. 389. 


\section{Heurística do temor}

$\mathrm{Na}$ atualidade não é por falta de prognoses ou de "previsões" (baseadas em pesquisas) que o ser humano ignora o futuro que o aguarda. No entanto, o teor de tais projeções parece não causar uma mudança no modo hodierno de agir. Assume-se o modus vivendi na era da técnica como se ele fosse o modo natural de viver. A aceleração das mudanças e do ritmo de vida contribuem cada vez mais para uma atitude de descarte do futuro em benefício do presente. Este imediatismo do viver para o aqui e agora, por um lado, e o estado hipnótico provocado pela magia da técnica por outro, não só inibem, mas também dispensam o homem contemporâneo de preocupar-se com o futuro distante. $\mathrm{Na}$ época em que ouvimos falar do "crepúsculo do dever" 21 , isto é, do obscurecimento da ética, da "liquidificação" das relações (tudo se torna líquido, fluído, desvanecido ${ }^{22}$ ), da política e da liberdade, parece não haver mais sentido defendermos princípios para a ética. Muito menos pertinente é querer apostar no temor, como critério para decisões. O que Jonas quer evidenciar com a apologia do temor? Quer ele retornar à ética dos sentimentos?

Jonas parte da constatação de que sabemos valorizar dialeticamente a vida como algo sagrado na medida em que conhecemos o que é sua aniquilação ou, por exemplo, através do mandamento "não matarás". A perda de algo ou a mera representação de sua perda, provoca instantaneamente uma valorização do mesmo objeto em questão. Da mesma forma, sabemos o que significa a liberdade por conhecermos o que é a sua falta, quando por exemplo ficamos presos a um leito enfermos ou nos imaginamos em uma prisão. Tais privações reais ou fictícias (representações de privações) podem ter um efeito positivo sobre nossa disposição e sobre o nosso agir. Com efeito, Kant já havia demonstrado que o ser humano é o único no reino da natureza, onde tudo age segundo leis determinadas, que, enquanto racional, tem a capacidade de agir segundo a mera representação de leis ${ }^{23}$.

Nesta perspectiva, Jonas entende que é possível que a previsão - não espontânea, mas intencional - de uma deformação do humano e da natureza possa contribuir para a preservação da humanidade e da natureza que

${ }^{21} \mathrm{Cf}$. LIPOVETSKY, 1992.

${ }^{22} \mathrm{Cf}$. BAUMANN, 2004.

${ }^{23} \mathrm{Cf}$. GMS, BA 15-16. 
queremos. "Nós precisamos de ameaças à imagem humana - e de tipos específicos de ameaças - para que com o pavor suscitado, nós consigamos assegurar uma imagem humana autêntica” ( $P V$, p. 63). E prossegue:

Pois assim acontece conosco: o reconhecimento do malum nos é infinitamente mais fácil do que o do bonum; é mais imediato, forçoso e muito menos exposto à diferenças de opinião e, acima de tudo, ele não é procurado: a simples presença horrível do mal se nos impõe, enquanto o bem pode permanecer aí discretamente, irrefletido (para o que nós devemos ter uma razão especial) e desconhecido. Sobre o mal nós não temos incertezas quando o experimentamos; sobre o bem temos certeza, na maioria das vezes, quando dele nos desviamos(PV, p. 63-64).

De acordo com Jonas, é justamente a partir desta certeza que temos do mal que queremos evitar e a imprecisão e incerteza do bem que queremos pois, sobre isso muito se discorda -, que devemos delimitar a esfera do exercício de nossa liberdade. Isto é, sabemos muito bem o que queremos que não nos aconteça ou, abreviadamente, temos consciência imediata sobre o que não queremos. Já para definir aquilo que queremos, talvez precisemos de muito mais tempo. O mal imaginado como conseqüência de nossas opções e ações (no futuro) deveria servir de contraponto ao agir concreto aqui e agora. Este mal imaginado deve assumir um caráter de mal experimentado. Eis o que o temor pode, segundo Jonas, oferecer enquanto princípio heurístico ${ }^{24}$. Com isso, o primeiro dever da ética do futuro é: entrever ou vislumbrar os efeitos de longo prazo de nossas ações. Pensar sobre as conseqüências da técnica, como de qualquer outra forma de ação humana, não apenas para o presente e sim considerando fundamentalmente o futuro, implica em uma reformulação da ética.

Neste sentido, a transformação jonasiana do imperativo de Kant é expressa nas seguintes proposições: "Aja de modo que os efeitos de tua ação sejam compatíveis com a permanência de uma autêntica vida humana sobre a Terra" ou ainda, formulado negativamente: "Aja de modo que os efeitos de

\footnotetext{
${ }^{24}$ Heurística, conforme o Philosophisches Wörterbuch (1991, p. 296), vem do grego heuriskein significa achar, encontrar. Além disso está relacionado à arte de inventar [Erfindungskunst] e à orientação, segundo métodos, para encontrar algo novo.
} 
tua ação não sejam destrutivos para a possibilidade de uma tal vida”. Ainda neste contexto o imperativo poderia ser assim expresso, de modo simples: "Não ponha em perigo as condições necessárias para a conservação indefinida da humanidade sobre a Terra" ou também, positivamente: "Inclua na tua opção presente a futura integridade do ser humano como um dos objetos do teu querer" ( $P V$, p. 36). Como se percebe Jonas apela de alguma forma para o critério da universalização, embora suas fórmulas permitam, de maneira semelhante a Kant, um espaço para a definição da ação concreta. Todavia, como já salientou-se anteriormente, isso não torna a ética de Jonas, uma ética do dever ou da autonomia nos moldes da ética kantiana.

\section{Considerações finais}

Através desta incursão na primeira parte da obra de Jonas foi possível, localizarmos os principais argumentos que sustentam - como ponto de partida - sua defesa veemente de uma nova ética. Iniciando sua argumentação pela consideração de que a técnica moderna introduziu uma transformação fundamental na noção de ação humana, Jonas pretende demonstrar que, apesar de a mesma ter se tornado nosso destino, ainda é possível a instauração de um princípio de precaução e preservação como marco regulador das ações humanas. É importante salientar que a sua proposta ética não se coloca como um sistema acabado da ética normativa ou da bioética.

A proposta de Jonas é alicerçada, como vimos, em duas críticas fundamentais, isto é, na crítica às éticas tradicionais e na crítica à técnica. Esta última está relacionada a ideia moderna de progresso e ao ideal baconiano de dominação da natureza. Esta dominação operada progressiva e exclusivamente através da técnica constitui-se para o autor na ameaça iminente de auto-aniquilação do ser humano. Face a esta ameaça, somente uma postura baseada em novos princípios - aos quais soman-se o temor e a reverência ante o estrago que pode surgir da ação humana - poderá abrir a possibilidade de pensarmos um futuro menos doloroso para a natureza e para as espécies, incluindo-se aí a espécie humana. Isso significa colocar o problema da tecnologia e da ciência no âmago da reflexão filosófica e ética, pois a ação humana já não pode mais ser pensada sem a técnica e sem o saber científico. Deste modo, por meio da inclusão da relação humana com a natureza e com o futuro desconhecido no cerne das preocupações éticas, o conceito de responsabilidade ganha um novo conteúdo. 
Ao operar com esta crítica às éticas da tradição, ao contrário do que pode parecer, Jonas não visa substituí-las ou mesmo eliminá-las. Neste sentido, o princípio responsabilidade poderia ser visto não como substituto, mas como complemento ou, até mesmo, atualização da ética, na medida em que os problemas de nosso tempo exigem mais elementos e considerações do que a tradição tem para oferecer.

Por isso mesmo é que se apresenta a exigência de um trabalho científico interdisciplinar que extrapola o próprio âmbito restrito da ética filosófica, conclamando todas as ciências à colaboração no estabelecimento de um novo patamar de relações, de uma nova posição sobre os problemas técnico-científicos. Se Jonas tem razão, então a filosofia contemporânea não pode mais se esquivar desta tarefa pois não está em condições de resolvê-la sozinha.

Cumpre assinalar, por fim, que as admoestações de Jonas não estão calcadas numa postura alarmista ou caprichosamente pessimista, apesar de dar margem para esta forma de interpretação de sua ética. Sobretudo sua heurística do temor é entendida enquanto uma simples apologia do medo, isto é, de que o sentimento patológico seria suficiente para mobilizar os seres agentes. Jonas não se refere a este tipo de comportamento e sim, é um apelo à razão técnica (ou instrumentalizada) para, como na época de Kant, comparecer no tribunal e submeter-se ao julgamento.

$\mathrm{O}$ avanço tecnológico tem indubitavelmente implicações morais. Para Jonas atrás disso está a pergunta: "o que fazemos com aquilo que sabemos?". Nesta perspectiva, sua ética da responsabilidade pretende contribuir, por um lado, para uma revisão e reformulação dos princípios, do ponto de vista filosófico e, por outro lado, para uma nova educação, com vistas à contenção da sede humana de dominação e voltada ao fomento de uma vida digna não apenas para a espécie humana, mas para a totalidade da natureza.

É certo, como salientamos, que a ética de Jonas não está isenta de problemas. A fundamentação do princípio responsabilidade permanece ainda para ser explorada em seus diversos aspectos. Um dos seus interlocutores, o filósofo K.-O. Apel, questiona, por exemplo, se somente uma ética da preservação e do cuidado é suficiente para dar conta tanto dos problemas teóricos, no plano da fundamentação, bem como dos problemas efetivos que se apresentam no campo prático ${ }^{25}$. Hösle pontua também objeções muito

${ }^{25} \mathrm{Cf}$. APEL, 1990. 
relevantes para a relação entre ontologia e ética na obra de Jonas. Estas críticas merecem, sem dúvida, um tratamento minucioso e implicam um trabalho a parte que aqui, por razões de espaço, não foi possível oferecer. Este tratamento detalhado faz parte, todavia dos objetivos da pesquisa que aqui se inicia. 


\section{Referências Bibliográficas}

APEL, K.-O. Diskurs und Verantwortung. Das Problem des Übergangs zur postkonventionellen Moral. Frankfurt am Main: Suhrkamp, 1990.

ARENDT, H. Vita Activa oder vom tätigen Leben. 4. Aufl. München: Piper Verlag, 2006.

BAUMANN, Z. Amor líquido: sobre a fragilidade dos laços humanos. Trad. Carlos A. Medeiros. Rio de Janeiro: Jorge Zahar, 2004.

BECCHI, P. "La ética en la era de la técnica. Elementos para una crítica a Karl-Otto Apel y Hans Jonas”. Doxa, Cuadernos de Filosofía del Derecho. Universidad de Alicante, 1989.

BIRNBACHER, D. Technik. In: MARTENS, E.; SCHNÄDELBACH, H. (Hrsg.). Philosophie: Ein Grunkurs. Bd. II. 7. Aufl. Reinbeck bei Hamburg: Rowohlt Taschenbuch Verlag, 2003.

BÖHLER, D. (Hrsg.). Ethik für die Zukunft. Im Diskurs mit Hans Jonas. München: C. H. Beck, 1994.

BÖHLER, D.; BRUNE, J. P. Orientierung und Verantwortung: Begegnungen und Auseinandersetzungen mit Hans Jonas. Würzburg: Königshausen und Neumann, 2004.

DEWITTE, J. "Préservation de l'humanité et image de l'homme". Études Phénoménologigues, 8. Bruxelles: Éditions Ousia, 1988.

DONNELEY, S. "Hans Jonas: La philosophie de la nature et l'éthique de la responsabilité”. In: Études Phénoménologigues, 8. Bruxelles: Éditions Ousia, 1988.

FONSECA, F. O. Hans Jonas: (bio)ética e crítica à tecnociência. Recife: Editora da UFPE, 2007.

GALIMBERTI, U. Psiche e Techne: o homem na idade da técnica. Trad. José Maria de Almeida. São Paulo: Paulus, 2006.

HABERMAS, J. Technik und Wissenschaft als Ideologie. 6. Aufl. Frankfurt am Main: Suhrkamp, 1973.

HEIDEGGER, M. Gelassenheit. 8. Aufl. Stuttgart: Verlag Günther Neske, 1985.

HESSE, Heidrum. Handlung. In: DÜWELL, M.; HÜBENTHAL, C.; WERNER, M. H. (Hrsg.). Handbuch Ethik. 2. Aufl. Stuttgart; Weimar: J. B. Metzler, 2006.

HÖSLE, V. "Hans Jonas Stellung in der Geschichte der deutschen Philosophie". In: WIESE, C.; JACOBSON, E. (Hrsg.). Weiterwohnlichkeit der Welt. Zur Aktualität von Hans Jonas. Berlin; Wien: Philo Verlag, 2003.

. “Ontologie und Ethik bei Hans Jonas”. In: BÖHLER, Dietrich (Hrsg.). Ethik für die Zukunft. Im Diskurs mit Hans Jonas. München: C. H. Beck, 1994. 
JONAS, H. Dem bösen Ende näher. Gespräche über das Verhältnis des Menschen zur Natur. Hrsg. von Wolfgang Schneider.Frankfurt am Main: Suhrkamp, 1993.

. Das Prinzip Verantwortung :Versuch einer Ethik für die technologische Zivilisation. Frankfurt am Main: Suhrkamp, 1984. . Memorias. Trad. Illana Giner Comín.Madrid: Editorial Losada, 2005. . Technik, Medizin und Ethik. Praxis des Prinzips Verantwortung. Frankfurt am Main: Suhrkamp, 1987.

KANT, I. Werke in sechs Bänden. Hrsg. von Wilhelm Weischedel. Darmstadt: Wissenschaftliche Buchgesellschaft, 1998.

LIPOVETSKY, G. Le Crépuscule du devoir. Paris: Gallimard, 1992.

MÜLlER, W. E. Hans Jonas: Philosoph der Verantwortung. Darmstadt: Wissenschaftliche Buchgesellschaft, 2008.

RITTER, J.; GRÜNDER, K.; GABRIEL, G. Historisches Wörterbuch der Philosophie. Basel: Schwabe Verlag, 1971-2007.

SCHMIDT, H. Philosophisches Wörterbuch. Neu bearb. Von Georgi Schischkoff. 22. Aufl. Suttgart: Kröner Verlag. 1991.

SPENGLER, O. Der Mensch und die Technik: Beiträge zu einer Philosophie des Lebens. München: C.H. Beck Verlag, 1931.

WERNER, M. “Hans Jonas' Prinzip Verantwortung”. In: DÜWELL, M.; STEIGLEDER, K. (Hrsg.). Bioethik: Eine Einführung. Frankfurt am Main: Suhrkamp, 2003.

WETZ, F. J. Hans Jonas: Eine Einführung. Hamburg: Junius Verlag, 1994.

WIESE, C.; JACOBSON, E. (Hrsg.). Weiterwohnlichkeit der Welt. Zur Aktualität von Hans Jonas. Berlin; Wien: Philo Verlag, 2003.

ZANCANARO, L. "A ética da responsabilidade de Hans Jonas". In: BARCHIFONTAINE, C. P.; PESSINI, L. (orgs.). Bioética: alguns desafios. São Paulo: Loyola; Centro Universitário São Camilo, 2001. 